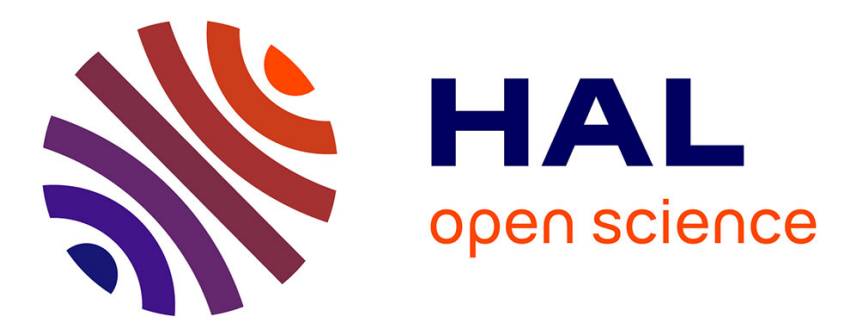

\title{
Interactions between the Cell Membrane Repair Protein S100A10 and Phospholipid Monolayers and Bilayers
} Xiaolin Yan, Kiran Kumar, Renaud Miclette Lamarche, Hala Youssef, Gary Shaw, Isabelle Marcotte, Christine Dewolf, Dror Warschawski, Elodie Boisselier

\section{To cite this version:}

Xiaolin Yan, Kiran Kumar, Renaud Miclette Lamarche, Hala Youssef, Gary Shaw, et al.. Interactions between the Cell Membrane Repair Protein S100A10 and Phospholipid Monolayers and Bilayers. Langmuir, 2021, 37 (32), pp.9652-9663. 10.1021/acs.langmuir.1c00342 . hal-03367662

\section{HAL Id: hal-03367662 https://hal.science/hal-03367662}

Submitted on 8 Oct 2021

HAL is a multi-disciplinary open access archive for the deposit and dissemination of scientific research documents, whether they are published or not. The documents may come from teaching and research institutions in France or abroad, or from public or private research centers.
L'archive ouverte pluridisciplinaire HAL, est destinée au dépôt et à la diffusion de documents scientifiques de niveau recherche, publiés ou non, émanant des établissements d'enseignement et de recherche français ou étrangers, des laboratoires publics ou privés. 


\section{Interactions between the cell membrane repair}

\section{protein S100A10 and phospholipid monolayers and bilayers}

Xiaolin Yan, ${ }^{1,2}$ Kiran Kumar, ${ }^{3}$ Renaud Miclette Lamarche, ${ }^{4}$ Hala Youssef, ${ }^{4}$ Gary S. Shaw, ${ }^{5}$

Isabelle Marcotte, ${ }^{3}$ Christine E. DeWolf, ${ }^{4}$ Dror E. Warschawski, ${ }^{3,6}$ and Elodie Boisselier ${ }^{* 1,2}$.

${ }^{1}$ Department of Ophthalmology, Faculty of Medicine, Université Laval, Quebec City, QC,

G1S 4L8 Canada; ${ }^{2}$ CUO-Recherche, Centre de Recherche du CHU de Québec, Hôpital du Saint-

Sacrement, CHU de Québec, Quebec City, QC, G1S 4L8 Canada; ${ }^{3}$ Departement of Chemistry,

Faculty of Sciences, Université du Québec à Montréal, Montreal, QC, H2V 0B3 Canada;

${ }^{4}$ Department of Chemistry and Biochemistry and Centre for NanoScience Research, Concordia

University, Montreal, QC, H4B 1R6 Canada; ${ }^{5}$ Departement of Biochemistry, Schulich School of

Medicine \& Dentistry, University of Western Ontario, London, ON, N6A 5C1 Canada; 
${ }^{6}$ Laboratoire des Biomolécules, LBM, CNRS UMR 7203, Sorbonne Université, École Normale Supérieure, PSL University, Paris, 75005 France

KEYWORDS: S100A10, Membrane binding, Langmuir monolayer, Ellipsometry, PROCSA.

ABSTRACT: Protein S100A10 participates in different cellular mechanisms and has different functions, especially at the membrane. Among those, it forms a ternary complex with annexin A2 and the C-terminal of AHNAK, and then joins the dysferlin membrane repair complex. Together, they act as a platform enabling membrane repair. Both AHNAK and annexin A2 have been shown to have membrane binding properties. However, the membrane binding abilities of S100A10 is not clear. In this paper, we aimed to study the membrane binding of S100A10 in order to better understand its role in the cell membrane repair process. S100A10 was overexpressed by E. coli and purified by affinity chromatography. Using a Langmuir monolayer as a model membrane, the binding parameters and ellipsometric angles of the purified S100A10 were measured using surface tensiometry and ellipsometry, respectively. Phosphorus-31 solid-state nuclear magnetic resonance spectroscopy was also used to study the interaction of S100A10 with lipid bilayers. In the presence of a lipid monolayer, S100A10 preferentially interacts with unsaturated phospholipids. In addition, 
its behavior in the presence of a bilayer model suggests that S100A10 interacts more with the negatively charged polar head groups than the zwitterionic ones. This work offers new insights on the binding of S100A10 to different phospholipids and advances our understanding of the parameters influencing its membrane behavior.

\section{INTRODUCTION}

S100A10 is a protein belonging to the S100 protein family. Most of the members of this family are called S100 because they can be solubilized in a saturated solution of ammonium sulfate at a neutral $\mathrm{pH}^{1}{ }^{1}$ As of 2020, 25 members of this family have been discovered in humans ${ }^{2}: \mathrm{S} 100 \mathrm{~A} 1$ S100A18, S100B, S100G, S100P, S100Z, filaggrin, repetin, and trichohyalin. ${ }^{3}$ Some classifications also consider "fused gene" proteins such as cornulin ${ }^{4}$, hornerin ${ }^{5-6}$ and filaggrin-2 ${ }^{6-7}$ as a subgroup of the $\mathrm{S} 100^{8}$ protein family. The $\mathrm{S} 100$ protein family is one of the subfamilies of EF-hand proteins. ${ }^{9-10}$ The name of EF-hand originally comes from the EF-hand motif found in parvalbumin, which is composed of two alpha helices "E" and "F" connected by an intermediate loop of 12 residues binding a calcium ion. ${ }^{11-12}$ In addition, all the S100 proteins undergo conformational changes upon binding calcium, except S100A10 13-14 and S100A14 ${ }^{15-16}$. S100A10 
has lost its ability to bind calcium due to substitutions in its calcium-binding loop, but retains the structure of a calcium-bound S100 protein. ${ }^{17}$

The S100 protein family has three specific characteristics differentiating them from the other EF-hand proteins: they have a different sequence for the two EF-hand motifs of the same protein, they are the only known EF-hand proteins having both homo- and heterodimeric conformations, ${ }^{18}$ and they are specifically expressed in different tissues and cells. ${ }^{19-20}$ S100 proteins are only expressed in vertebrates. ${ }^{21}$ S100A10 is highly expressed in lungs, kidneys and intestine. S100A10 is also present in different types of cells such as endothelial cells, epithelial cells, macrophages, fibroblasts and even in some cancer cell lines. ${ }^{22}$

It is of great interest to study S100A10 because this protein participates in different cellular mechanisms and has different functions, especially at the membrane. ${ }^{19,21,23}$ The role of S100A10 is increasingly being studied in breast, stomach and kidney cancer research, and it has been proposed to be a potential biomolecular marker for early gallbladder cancer diagnostics and therapeutic applications. ${ }^{24-25}$ S100A10 forms a heterotetramer with annexin A2 regulating exocytosis and endocytosis. ${ }^{26}$ One potential mechanism of action of S100A10 is that it forms a ternary complex with annexin A2 and the C-terminal of AHNAK, and then is recruited by the dysferlin membrane repair complex. Together, they act as a platform enabling membrane repair. ${ }^{27-}$ 30 This dysferlin membrane repair complex, activated by calcium, could support the fusion of exocytosis vesicles that expand, and the inner side of the membrane would thus be resealed. ${ }^{31-34}$ 
Thus, it is crucial to understand the interaction between the lipid membrane and this complex in order to understand the cell membrane repair process as a whole. In the presence of calcium, annexin A2 and S100A10-annexin A2 heterotetramer are able to repair vesicles containing phosphatidylserine, phosphatidylinositol and phosphatidic acid. ${ }^{35-36}$ Our recent study demonstrates that a peptide composed of the 20 amino acids (G5654 - L5673) of the C-terminal domain of AHNAK (pAHNAK) preferentially and strongly interacts with phospholipids composed of negatively charged polar head groups with unsaturated acyl chains. ${ }^{37}$ However, it is not clear whether S100A10 is also involved in interactions with lipids found in the cell membrane. S100A10 has been shown as one important member of the dysferlin membrane repair complex and its direct interaction with annexin A2 and AHNAK has been demonstrated using coimmunoprecipitation and yeast three-chimeric experiments. ${ }^{34,} 38-39$ Furthermore, knockdown of S100A10 prevents AHNAK from localizing to the membrane, suggesting here the very important role of S100A10 at the membrane. Finally, annexin A2-mediated linking of membrane surfaces under non-oxidative intracellular conditions probably requires annexin A2-S100A10 complex formation, highly suggesting a major role of S100A10 at the membrane..$^{40}$ Multiple studies have shown that annexin A2 is the driving force for association of the S100A10-annexin A2 complex with membrane surfaces. ${ }^{41-42}$ However, differences have been noted when membrane binding of the S100A10annexin A2 complex is compared with annexin A2 alone $e^{40,43-45}$ that suggest involvement of S100A10. Also, it has been shown that the binding of S100A10 to annexin A2 reduces the calcium dependency of membrane interaction of annexin A2 from millimolar to micromolar levels of intracellular calcium, thus facilitating the membrane interaction of annexin A2 with less calcium. ${ }^{35}$ Further, surfaces plasmon resonance experiments have shown that S100A10 binds approximately 10-fold weaker to $\mathrm{POPC} / \mathrm{POPE} / \mathrm{PtdIns}(4,5) \mathrm{P}_{2}$ or $\mathrm{POPC} / \mathrm{POPE} / \mathrm{PtdIns}(3) \mathrm{P}$ vesicles than the 
S100A10-annexin A2 complex. ${ }^{45}$ To explain all of these phenomena, we hypothesize that S100A10 provides a secondary interaction site that interacts weakly with the cell membrane and this manuscript offers a new insight into this possibility.

Our present research investigates the membrane binding of purified S100A10 with the use of two membrane models (the Langmuir monolayer model and a lipid bilayer model) and various biophysical techniques (surface tensiometry, ellipsometry, and ${ }^{31} \mathrm{P}$ solid-state nuclear magnetic resonance (NMR) spectroscopy). As S100A10 is a S100 protein which does not undergo conformational changes upon binding calcium, experiments have been conducted only in the presence of calcium ions. Future studies of the membrane behavior of this protein complexed with calcium sensitive proteins will also need to consider the influence of calcium. ${ }^{13-14}$ The Langmuir monolayer model can be considered as an asymmetric cell membrane and it allows a more in-depth study of the processes at the membrane interface. ${ }^{46}$ It allows a good control over a number of experimental parameters including the buffer, the physical state of the lipids that are used, and surface pressure. ${ }^{46-47}$ Conversely, multilayer vesicles are made of several lipid bilayers; the preparation of these vesicles is relatively easy and no support is required for them. They are also known to provide a satisfactory signal for NMR analysis. ${ }^{48}$ The results described below shed light 
on the membrane behavior of S100A10 in the membrane repair process and its other roles in which

lipids are involved.

\section{EXPERIMENTAL SECTION}

Materials. The deionized water used throughout the experiments was from a Barnstead Nanopure

system (Barnstead, Dubuque, IA, USA) and its resistivity and surface tension at $20^{\circ} \mathrm{C}$ were 18.2

$\mathrm{M} \Omega \cdot \mathrm{cm}$ and $72 \mathrm{mN} / \mathrm{m}$, respectively. E. coli BL21-CodonPlus (DE3)-RIL Competent Cells and

XL10-Gold $\beta$-mercaptoethanol were from Agilent Technologies (Santa Clara, CA, USA).

Tryptone, yeast extract, ampicillin sodium salt, isopropyl $\beta$-D-1-thiogalactopyranoside (IPTG),

glycerol, Tris Base, reduced glutathione, ethylenediaminetetraacetic acid (EDTA) disodium salt

dihydrate, dithiothreitol (DTT), sodium dodecyl sulfate (SDS), glycine, ammonium persulfate

(APS), SeeBlue Pre-Stained Protein Standard, and 2,6-Di-tert-butyl-4-methylphenol were

purchased from Fisher Scientific (Hampton, NH, USA). $\mathrm{NaCl}, \mathrm{KCl}$, lysozyme, anhydrous

$\mathrm{Na}_{2} \mathrm{HPO}_{4}, \mathrm{KH}_{2} \mathrm{PO}_{4}$, acetic acid glacial, hydrochloric acid and high-range rainbow molecular

weight markers were obtained from VWR International (Radnor, PA, USA). Anhydrous D-

Glucose, bromophenol blue and Coomassie brilliant blue R-250 were from Bio Basic (Toronto, 
ON, Canada). 30\% Acrylamide/Bis solution and 2-mercaptoethanol (14.2 M) were purchased from

Bio-Rad Laboratories (Berkeley, CA, USA). Ethanol 100\% was from Greenfield Global (Toronto,

ON, Canada). PreScission protease (PSP) was from Cedarlane Laboratories (Burlington, ON,

Canada). The GST affinity chromatography columns, GSTrap FF (5 mL) and GSTrap FF (5 mL),

were obtained from GE Healthcare (Chicago, IL, USA). High performance liquid

chromatography-grade chloroform and methanol came from Laboratoire Mat (Quebec, QC,

Canada). The following phospholipids were purchased from MilliporeSigma (Burlington, MA,

USA) with a purity > 99\%: 1,2-dipalmitoyl-sn-glycero-3-phosphoethanolamine (DPPE), 1,2-

dipalmitoyl-sn-glycero-3-phospho-L-serine (sodium salt) (DPPS), 1,2-dipalmitoyl-sn-glycero-3-

phosphocholine (DPPC), 1,2-distearoyl-sn-glycero-3-phosphoethanolamine (DSPE), 1,2-

distearoyl-sn-glycero-3-phospho-L-serine (sodium salt) (DSPS), 1,2-distearoyl-sn-glycero-3-

phosphocholine (DSPC), 1,2-dioleoyl-sn-glycero-3-phosphoethanolamine (DOPE), 1,2-dioleoyl-

sn-glycero-3-phospho-L-serine (sodium salt) (DOPS), 1,2-dioleoyl-sn-glycero-3-phosphocholine

(DOPC), 1,2-didocosahexaenoyl-sn-glycero-3-phosphoethanolamine $\quad$ (DDPE), 1,2-

didocosahexaenoyl-sn-glycero-3-phospho-L-serine (sodium salt) (DDPS), and 1,2-

didocosahexaenoyl-sn-glycero-3-phosphocholine (DDPC). The lipid solutions were prepared in 
chloroform, except for DSPS which was solubilized in a mix of chloroform, methanol and water $(65: 25: 4 \mathrm{v} / \mathrm{v})$, in concentrations ranging from 0.1 to $0.2 \mathrm{mg} / \mathrm{mL}$. 2,6-Di-tert-butyl-4-methylphenol $(5 \mu \mathrm{g} / \mathrm{mL})$ was added to the unsaturated lipids as an antioxidant ${ }^{49}$ and these were cautiously protected under argon. Saturated lipids were simply kept under atmospheric air. A low temperature of $-20^{\circ} \mathrm{C}$ was chosen to store all the lipids and lipid solutions.

S100A10 overexpression and purification. The complete protocol of transformation, overexpression and purification of S100A10 was recently published. ${ }^{50}$ Briefly, GST-S100A10 was overexpressed in E. coli BL21-Codon Plus (DE3)-RIL. Bacterial cultures in $1 \mathrm{~L}$ of LB ampicillin medium were incubated at $37{ }^{\circ} \mathrm{C}, 250 \mathrm{rpm}$ until the optical density at $600 \mathrm{~nm}($ O.D. $.600 \mathrm{~nm})$ reached 0.8. Overexpression was started by the addition of $10 \mathrm{~mL}$ of $100 \mathrm{mM}$ isopropyl $\beta-\mathrm{D}-1-$ thiogalactopyranoside (IPTG) into the cultures, keeping the incubation at $21{ }^{\circ} \mathrm{C}, 250 \mathrm{rpm}$ for 16 hours. Bacterial cultures were centrifuged at $3270 \mathrm{~g}, 4^{\circ} \mathrm{C}$ for $30 \mathrm{mins}$, and only the cell pellet was kept. Cell lysis was done with lysozyme in PBS (1X), followed by 3 cycles of freeze-thaw and sonication. Lysed cells were centrifuged at $15000 \mathrm{~g}, 4{ }^{\circ} \mathrm{C}$ for $30 \mathrm{mins}$, and the supernatant and cell pellet were suspended into the same volume of PBS (1X). After verification by $12 \%$ SDS-

PAGE, the supernatant was loaded on two GSTrap FF $(5 \mathrm{~mL})$ columns connected at $4{ }^{\circ} \mathrm{C}$ to purify 
GST-S100A10. Contaminants were removed by several washes of the columns. Eluted fractions were collected and deposited on a 12\% SDS-PAGE gel. Fractions containing GST-S100A10 were mixed together, and to remove excess glutathione, a buffer-exchange with a basic buffer (50 mM Tris and $100 \mathrm{mM} \mathrm{NaCl}, \mathrm{pH} \mathrm{9.5)} \mathrm{and} \mathrm{a} \mathrm{centrifugal} \mathrm{filtration} \mathrm{were} \mathrm{done} \mathrm{before} \mathrm{cleaving} \mathrm{the} \mathrm{GST.}$ After $2 \mathrm{~h}$ cleavage at $4{ }^{\circ} \mathrm{C}$, the sample was loaded on a GSTrap FF (5 mL) column connected with a GSTrap HP (5 mL) column to purify S100A10 (11.203 kDa). Several fractions were obtained from the washes of the columns and deposited on a $17 \%$ SDS-PAGE gel. The scanned image of this SDS-PAGE was analyzed by ImageJ to determine the purity of S100A10. The fractions containing S100A10 with a purity $\geq 95 \%$ were stoked at $-20{ }^{\circ} \mathrm{C}$ for further studies.

Surface Pressure Measurements. The Wilhelmy method was used to determine the surface tension, from which the protein binding parameters can be extrapolated. ${ }^{51-52}$ A DeltaPi4 microtensiometer (Kibron Inc., Helsinki, Finland) and a 1000- $\mu \mathrm{L}$ Teflon ${ }^{\circledR}$ trough (diameter: 18 $\mathrm{mm}$, depth: $5 \mathrm{~mm}$ ) were used to measure the surface pressure $(\Pi)$. The humidity was controlled throughout the experiments using a Plexiglass box while the experimental temperature was maintained at $20^{\circ} \mathrm{C} \pm 1{ }^{\circ} \mathrm{C} .1000-\mu \mathrm{L}$ of buffer comprising $20 \mathrm{mM}$ Tris and $100 \mathrm{mM} \mathrm{NaCl}$ at $\mathrm{pH}$ 7.30 was defined as the subphase of the trough, without any stirring. To determine the saturating 
(equilibrium) concentration, increasing volumes of S100A10 were injected underneath the surface

of the subphase the saturating concentration was determined to be $34.8 \mu \mathrm{g} / \mathrm{mL}$ corresponding to an equilibrium surface pressure of $17.0 \mathrm{mN} / \mathrm{m}$ (see Figure $\mathrm{S} 1$ ). This concentration was considered as the onset of monolayer saturation and should be used for all the following experiments.

For the subsequent monolayer experiments, a few microliters of a given phospholipid solution were first deposited onto the subphase. The solvent was left to spread and evaporate, and the phospholipid film reached equilibrium at the initial surface pressure $\left(\Pi_{i}\right)$. The type of lipid, the spreading volume and the initial surface pressure all influenced the time needed for this. ${ }^{53-54}$ S100A10 was then injected underneath the lipid monolayer in order to obtain the saturating concentration of $34.8 \mu \mathrm{g} / \mathrm{mL}$ (the stock solution concentration was $2.32 \mathrm{mg} / \mathrm{mL}$ ). The interaction between the S100A10 and the phospholipid monolayer was monitored by measuring the surface pressure until the equilibrium surface pressure $\left(\Pi_{\mathrm{e}}\right)$ was reached. The surface pressure variation $(\Delta \Pi)$ corresponds to $\Pi_{\mathrm{e}}-\Pi_{\mathrm{i}}$ and is attributed to the presence of the protein.

Determination of the Binding Parameters. The methods of binding parameters and uncertainties calculation have already been described. ${ }^{47,} 49,53-59$ The change in surface pressure $(\Delta \Pi)$ resulting from the injection of S100A10 was plotted against $\Pi_{i}$ and fitted by linear regression (Figure $S 2$ ). 
The maximum insertion pressure (MIP) could be determined from the intersection of the plot with the $x$-axis and its uncertainty was calculated from the covariance of the experimental data on the regression. Furthermore, the synergy is defined as $1+$ the slope while its uncertainty corresponds to $\left(\sigma\left(\Pi_{\mathrm{e}}\right)\left(1-\mathrm{r}^{2}\right)^{1 / 2}\right) /\left(\sigma\left(\Pi_{\mathrm{i}}\right)(\mathrm{n}-2)^{1 / 2}\right)$, where $\sigma$ is the standard deviation, $\mathrm{r}$ the correlation coefficient, and $\mathrm{n}$ the number of points. All these calculations were made using an online software (http://www.crchudequebec.ulaval.ca/BindingParameters Calculator).

Ellipsometry Measurements. A polarizer compensator specimen analyzer null imaging ellipsometer was used for ellipsometry measurements (I-Elli2000; Nanofilm, now Accurion GmbH, Goettingen, Germany) and a 532 nm, $50 \mathrm{~mW} \mathrm{Nd:YAG} \mathrm{laser} \mathrm{was} \mathrm{used.} \mathrm{Given} \mathrm{the} \mathrm{Brewster}$ angle of the air-water interface for pure water is $53.12^{\circ}$, all ellipsometry measurements were made at an angle of incidence of $50^{\circ}$ to the air-water interface. The laser output was set to $100 \%$ with the compensator set at $20.00^{\circ} .54,60$ In order to minimize the influence of the lateral structure or defects within the beam spot and maintain spatial information, the ellipsometric angles $\Delta$ were measured for different regions of interest, with a size $\geq 20 \mu \mathrm{m}$. This helps to ensure the results were accurate and reproducible. ${ }^{37} \mathrm{~A}$ mean of thirty experimental measurements was used for representing each set of conditions. The Langmuir trough used for the ellipsometry measurements 
was a home-made Teflon ${ }^{\circledR}$ well with a volume of 5000- $\mu \mathrm{L}$. Buffer containing $20 \mathrm{mM}$ Tris and 100

$\mathrm{mM} \mathrm{NaCl}$ at $\mathrm{pH} 7.3$ was used as subphase. The surface pressure was monitored using the Wilhelmy method via a tensiometer (Nima Technology, Coventry, UK). The experiment temperature was set at $20^{\circ} \mathrm{C} \pm 1^{\circ} \mathrm{C}$. The protein was injected to obtain the saturating concentration $(34.8 \mu \mathrm{g} / \mathrm{mL})$, as described above.

Ellipsometric Angle Determination. For the first step of each ellipsometric experiment, it was necessary to measure the ellipsometric angle of the subphase (i.e., the buffer), $\Delta_{\text {subphase, }}$, as the baseline. For the measurement of S100A10 alone, without an overlying lipid monolayer, S100A10 was again injected at the saturating concentration of $34.8 \mu \mathrm{g} / \mathrm{mL}$. The kinetics of changes in surface pressure (reflecting the adsorption of the protein to the interface) were recorded until the equilibrium surface pressure $\left(\Pi_{e}\right)$ was reached. At the same time, the ellipsometric angles were measured every $15 \mathrm{~min}$. For measuring the lipid baseline, an initial pressure of $10 \mathrm{mN} / \mathrm{m}$ was made by spreading a few microliters of phospholipid solution on the subphase. The measurements of ellipsometric angles were performed as described above for S100A10, DOPC, DOPE, and DOPS, referred to as $\Delta_{\mathrm{S} 100 \mathrm{~A} 10}, \Delta_{\mathrm{DOPC}}, \Delta_{\mathrm{DOPE}}$, and $\Delta_{\mathrm{DOPS}}$, respectively. To eliminate the influence of the subphase, each value was corrected by subtracting the value of $\Delta_{\text {subphase. }}$ For the study of the 
interaction between a lipid and the protein, a desired initial pressure $(10 \mathrm{mN} / \mathrm{m})$ was used by spreading the lipid on the subphase, the injection of S100A10 was then performed at $34.8 \mu \mathrm{g} / \mathrm{mL}$ and ellipsometric angles measured every 15 min until the equilibrium surface pressure $\left(\Pi_{\mathrm{e}}\right)$ was reached. The experimental value was denoted as $\Delta_{\mathrm{S} 100 \mathrm{~A} 10-\text { lipid }}$ and the expected value was defined as the sum of $\Delta_{\mathrm{S} 100 \mathrm{~A} 10}$ and $\Delta_{\text {lipid }}$. For measurements at the air-water interface, the changes in the elipsometric angle $\Psi$ are not small enough to be under the limit of detection and thus only changes to $\Delta$ are reported. These changes in $\Delta$ are then directly related to the optical properties (thickness, extinction coefficient and refractive index) of the films. For transparent organic monolayers at the air-water interface, the extinction coefficient and refractive index can be considered constant and therefore $\Delta$ reflects changes in the total film thickness. For lipid-protein films, the refractive index lies between 1.4 and 1.5 and variations in the refractive index within this range do not affect the value of $\Delta$ which is primarily governed by thickness. ${ }^{61}$ Comparison between them helps to understand the insertion depth of protein in lipid.

Multilayer vesicles preparation. The samples for ${ }^{31} \mathrm{P}$ solid-state NMR measurements were prepared by first solubilizing $6.7 \mathrm{mg}$ of DOPE, DOPS and DOPC (1:1:1 molar ratio) in chloroform and drying them under argon steam on ice. Then, $2 \mathrm{mg}$ of S100A10 at $200 \mu \mathrm{M}$ solubilized in a 
buffer (20 mM Tris and $100 \mathrm{mM} \mathrm{NaCl}$ at $\mathrm{pH} 7.3$ ) was added into the lipid mixture. At the same time, a control group was prepared by adding an equal volume of buffer without protein into the lipid mixture. All the samples were lyophilized overnight to remove the residual organic solvent and water. The next morning, each sample was hydrated by adding $26 \mu \mathrm{L}$ of deionized water. The samples were subsequently subjected to three cycles of vortexing and freeze-thawing (10 min at $20^{\circ} \mathrm{C}$, then $10 \mathrm{~min}$ at room temperature) to create multilamellar lipid vesicles. Finally, 25-30 mg of sample were put in a disposable Kel-F insert, then placed in a 4-mm rotor for analyzing.

${ }^{31}$ P Solid-State NMR Measurements. To keep the same temperature as the membrane binding measurements, each experiment was run in duplicate at $20^{\circ} \mathrm{C}$. Then, to adapt to the human body's physiological temperature, each experiment was run at $37^{\circ} \mathrm{C}$.

A 400-MHz solid-state NMR Bruker Avance III-HD wide-bore spectrometer (Bruker, Milton, Ontario, Canada) was used for PROCSA experiments, the conditions were a frequency of 162 $\mathrm{MHz}$ for ${ }^{31} \mathrm{P}$ and a $4-\mathrm{mm}$ double resonance MAS probe was used. ${ }^{47}$ The spinning frequency of the samples was set at $6 \mathrm{kHz}$, and a minimum equilibration time of 15 min was performed between each step of temperature change. The field strength used for PROCSA pulses was around $25 \mathrm{kHz}$, $3 \mu$ s was set for the phosphorus $\left(90^{\circ}\right)$ pulse length. The field strength used for two-pulse phase 
modulation proton decoupling during acquisition was set at $25 \mathrm{kHz}$. For acquiring twodimensional spectra, 256 scans for each of the 32 rows and a recycle delay of $3 \mathrm{~s}$ were needed, 7 $\mathrm{h}$ were required to accomplish this step. Data analyzing was performed with the Bruker TopSpin 3.5 interface, automatic baseline correction and $5 \mathrm{~Hz}$ of line broadening was used. The chemicalshift anisotropy determination has a precision of $\pm 2 \mathrm{ppm}$.

\section{RESULTS AND DISCUSSION}

Purification of S100A10. The S100A10 (11.203 kDa, according to its sequence in the UniProt Knowledge Base, Q6SQH4) used in our study is a protein from Oryctolagus cuniculus (Rabbit), which has a 100\% identity with the S100A10 (UniProt Knowledge Base, P60903) from Homo sapiens (Human). GST-S100A10 gene carried by pGEX-6P-1 vector was transformed into E. coli,

then overexpressed and purified by Glutathione S-transferase (GST) affinity chromatography. ${ }^{50,62}$ The GST tag was cleaved by PreScission protease (PSP). After the cleavage, the obtained sequence contains five additional residues compared to the native S100A10, GPLGS, at the beginning of the N-terminal segment. Excess glutathione was removed by centrifugal filtration and buffer-exchange, and the GST tag was removed by a second GST affinity chromatography. LC/MS-MS (Proteomics 
Platform, Centre de Recherche du CHU de Québec, QC, Canada) was used to analyze the SDS-

PAGE gel containing S100A10 and it showed an identity as S100A10 with 100\% probability. The purity of S100A10 was analyzed by ImageJ and was superior to $97 \%$ (see the image of the Coomassie stained gel of the purified S100A10 in the Supplementary Information, Figure S3). Pure S100A10 was analyzed by circular dichroism at different temperatures for different times and the results indicated that $\mathrm{S} 100 \mathrm{~A} 10$ is stable at $4,20,-20$ or $-80^{\circ} \mathrm{C}$ for, at least, 60 days (see the circular dichroism spectra of S100A10 in the Supplementary Information, Figure S4). Thus, S100A10 will be stable during the analysis at $20^{\circ} \mathrm{C}$ and its storage will be performed at $-80^{\circ} \mathrm{C}$.

Determination of the Membrane Binding Parameters of S100A10. Even through there is no data available on the interaction between S100A10 and lipids, it is known that S100A10 forms a ternary complex with annexin A2 and the C-terminal of AHNAK, as a part of the dysferlin membrane repair complex. Indeed, they work together as a platform enabling membrane repair. ${ }^{27-30}$ As the interaction between the peptide of the AHNAK C-terminal (pAHNAK) and 12 phospholipids was well reported in our recent study ${ }^{37}, \mathrm{~S} 100 \mathrm{~A} 10$ was studied with the same biophysical techniques to understand its roles and functions in the complex, as well as on the mechanism of membrane repair. 
To be able to compare the membrane interaction of S100A10 with that of pAHNAK, the same 12 phospholipids were used in the following study.

Phospholipids have two main parts, one being a hydrophilic polar head group, either negatively charged or zwitterionic, and a hydrophobic tail of two acyl chains that may either be saturated or unsaturated. These different characteristics could largely affect their interactions with proteins. Indeed, those having a negatively charged polar head group (e.g., phospho-L-serine) are prone to interact with positively charged proteins. But size also plays an important role for lipid-protein interactions: phosphocholine and phosphoethanolamine are both zwitterionic, however the former is significantly larger than the latter and alters both the polar head group and chain packing constraints. As a result, lipid-protein interactions may be affected, particularly if a protein is inserted into the membrane. ${ }^{63-64}$ The physical state and the lipid phase could also be influenced by the presence of unsaturated bonds in the acyl chains, impacting the membrane organization and thus lipid-protein interactions.

Twelve phospholipids, with different combinations of polar head groups and acyl chains, were used with the Langmuir monolayer model membrane. Six of them had saturated acyl chains, among which DPPE, DPPS and DPPC are diC16:0 (meaning they have two acyl chains of palmitic 
acid, i.e., 16 carbons with 0 unsaturation) while DSPE, DSPS and DSPC are diC18:0 (with stearic acid chains). The six other phospholipids were unsaturated: DOPE, DOPS and DOPC are diC18:1 (oleic acid), and DDPE, DDPS and DDPC are diC22:6 (docosahexaenoic acid).

One of the binding parameters measured in these experiments is the maximum insertion pressure (MIP). It represents the pressure from which a protein can no longer insert into a lipid membrane. ${ }^{55}$ Higher values of MIP indicate stronger affinities between the protein and the lipid membrane.

The second binding parameter measured in these experiments is the synergy. It indicates the type of interaction taking place between the protein and the lipid monolayer. When the synergy has a positive value, there is an overall attraction between the protein and lipids. However, when the synergy is negative, it indicates repulsion between them. The synergy and MIP values for S100A10 with the 12 lipids that were studied are presented in Figure 1 and Table S1 (supplementary information). 


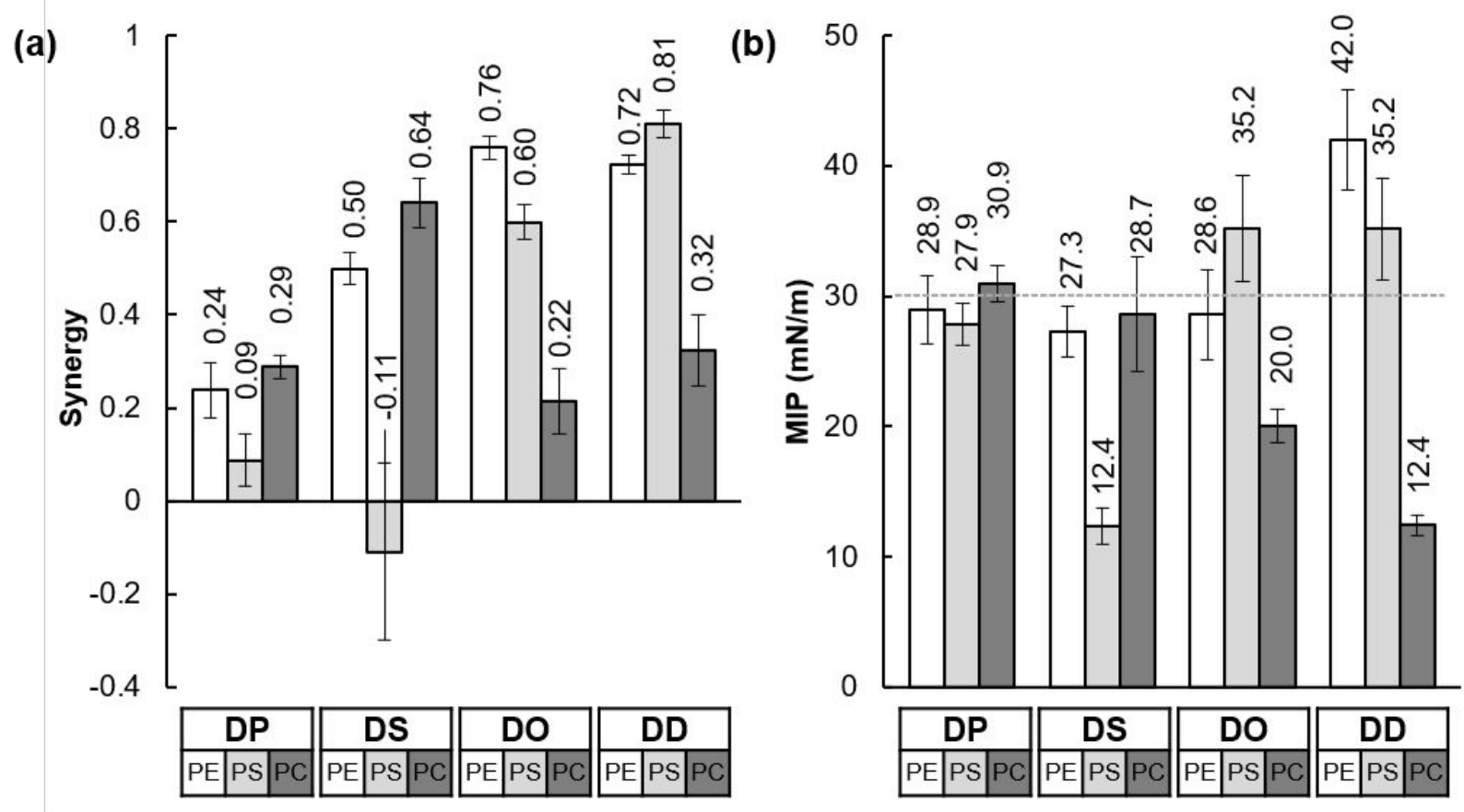

Figure 1. Bar plot showing the synergy values (a) and maximum insertion pressure (MIP) values

(b) of S100A10 for the 12 phospholipids. Chains: DP, dipalmitoyl; DS, distearoyl; DO, dioleoyl;

DD, didocosahexaenoyl. Polar head groups: PE, phosphoethanolamine; PS, phosphoserine; PC,

phosphocholine.

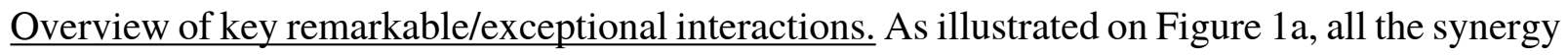

values are higher than zero, except for interaction of S100A10 with DSPS. This observation suggests that the interactions between S100A10 and all these lipids are positive, except for DSPS where the phospholipid monolayer seems to be repulsive towards S100A10. This phenomenon shows that the distearoyl (DS) acyl chains packing leads to a lipid organization which disrupts the 
binding of S100A10 compared to other acyl chains with the same phosphoserine (PS) polar head group. The MIP value of DSPS $(12.4 \pm 1.4)$ is also one of the lowest values, along with DDPC (12.4 \pm 0.7$)$. By comparison, DDPS shows the highest synergy value $(0.81 \pm 0.03)$ of all the lipids.

Regarding the MIP, the values observed with DSPE, DPPS, DSPS and the unsaturated phospholipids composed of a phosphocholine (PC) polar head group (DOPC and DDPC) are all inferior to $30 \mathrm{mN} / \mathrm{m}$ (Figure 1b). As a result, S100A10 may not, in a physiological context, easily insert into domains composed mainly of these types of phospholipids. Indeed, because the lateral pressure of the membrane is estimated to be around $30 \mathrm{mN} / \mathrm{m},{ }^{54,65-70} \mathrm{MIP}$ values $<30 \mathrm{mN} / \mathrm{m}$ (value illustrated with the gray dashed line on Figure 1b) indicate that S100A10 could not insert into a membrane in these cases.

The equilibrium surface pressure of S100A10 alone at the saturating concentration was $17.0 \mathrm{mN} / \mathrm{m}$. Except for DSPS and DDPC, the other phospholipids had MIP values higher than this value, suggesting that S100A10 is highly attracted by the lipid monolayer containing those ten phospholipids, in comparison with the air/water interface. The highest MIP value was observed in the presence of unsaturated lipids with PE and PS headgroups, and since those lipids also presented 
high synergy values, it would suggest S100A10 could preferentially interact with domains that are rich in unsaturated PS and PE lipids in a physiological context.

Influence of the polar head group. The MIP and synergy values were analyzed and compared for each polar head group type. Considering first the phosphoethanolamine (PE) polar head group, for the saturated phospholipids, the MIP values for the two saturated lipids were similar: DSPE $(27.3 \pm 1.9 \mathrm{mN} / \mathrm{m})$ and DPPE $(28.9 \pm 2.6 \mathrm{mN} / \mathrm{m})$, but the synergy value for DSPE $(0.50 \pm 0.03)$ was significantly higher than the synergy value for DPPE $(0.24 \pm 0.06)$. When comparing saturated phospholipid DSPE and monounsaturated acyl chains of phospholipid DOPE, both of them having the same acyl chain length, the MIP values were again similar, DOPE $(28.6 \pm 3.4 \mathrm{mN} / \mathrm{m})$ and DSPE $(27.3 \pm 1.9 \mathrm{mN} / \mathrm{m})$, however, the synergy value of the unsaturated DOPE $(0.76 \pm 0.03)$ was clearly higher than DSPE $(0.50 \pm 0.03)$. With polyunsaturated and monounsaturated lipids, the MIP value for the polyunsaturated DDPE $(42.0 \pm 3.8 \mathrm{mN} / \mathrm{m})$ was much higher despite similar synergy values for the unsaturated lipids $(0.72 \pm 0.02$ for DDPE and $0.76 \pm 0.03$ for DOPE). So, with the zwitterionic PE polar head group, these results suggest that S100A10 preferentially interacts with unsaturated lipids. Moreover, a high number of unsaturations of acyl chain largely improves the interaction between S100A10 and phospholipid monolayers. 
With the anionic PS polar head group, when considering the two saturated phospholipids, the MIP value for the slightly longer-chain DSPS $(12.4 \pm 1.4 \mathrm{mN} / \mathrm{m})$ was much lower than DPPS (27.9 $\pm 1.6 \mathrm{mN} / \mathrm{m}$ ) and their synergy values followed the same trend, with $-0.11 \pm 0.19$ and $0.09 \pm 0.06$ respectively. Comparing the saturated phospholipid DSPS and monounsaturated phospholipid DOPS, with the same acyl chain length, the MIP and synergy values of DOPS $(35.2 \pm 4.0 \mathrm{mN} / \mathrm{m}$ and $0.60 \pm 0.04$, respectively) were distinctly higher than DSPS $(12.4 \pm 1.4 \mathrm{mN} / \mathrm{m}$ and $-0.11 \pm$ 0.19 , respectively). Finally, the MIP value of the polyunsaturated DDPS $(35.2 \pm 3.9 \mathrm{mN} / \mathrm{m})$ was the same as that of the monounsaturated DOPS $(35.2 \pm 4.0 \mathrm{mN} / \mathrm{m})$, but DDPS $(0.81 \pm 0.03)$ had a higher synergy value than DOPS $(0.60 \pm 0.04)$. Thus, with PS polar head group again, S100A10 preferentially interacts with unsaturated acyl chains, with a notable preference for polyunsaturated phospholipids rather than monounsaturated phospholipids.

For the zwitterionic PC polar head group, with the saturated phospholipids, the MIP value for DSPC $(28.7 \pm 4.4 \mathrm{mN} / \mathrm{m})$ was similar to DPPC $(30.9 \pm 1.4 \mathrm{mN} / \mathrm{m})$, however, DSPC $(0.64 \pm 0.05)$ had a distinctly higher synergy value than DPPC $(0.29 \pm 0.03)$; this was the same observation as with the saturated zwitterionic PEs. However, the similarity of PE and PC does not hold when considering the influence of an addition of a unit of unsaturation. In the case of PC polar headgroup, 
the presence of one unsaturation lowered the MIP and synergy values: DOPC $(20.0 \pm 1.3 \mathrm{mN} / \mathrm{m}$, $0.22 \pm 0.07)$ versus DSPC $(28.7 \pm 4.4 \mathrm{mN} / \mathrm{m}, 0.64 \pm 0.05$. Increasing the units of unsaturation has the effect of further lowering the MIP, DDPC $(12.4 \pm 0.7 \mathrm{mN} / \mathrm{m})$, but with less distinction between their synergy values $0.32 \pm 0.08$ and $0.22 \pm 0.07$ for DDPC and DOPC, respectively. Contrary to the trends observed with PS and PE polar head groups, S100A10 preferentially interacts with the saturated phospholipids which have longer acyl chains in the presence of a PC polar head group and in this case, the presence and the number of unsaturations of acyl chains disadvantage the interaction between S100A10 and phospholipid monolayers.

Furthermore, comparing the phospholipids with the highest preference by S100A10 for each different polar head group, it was found that DDPE $(0.72 \pm 0.02$ and $42.0 \pm 3.8 \mathrm{mN} / \mathrm{m})$ and DDPS $(0.81 \pm 0.03$ and $35.2 \pm 3.9 \mathrm{mN} / \mathrm{m})$ had higher binding parameters values than DSPC $(0.64 \pm 0.05$ and $28.7 \pm 4.4 \mathrm{mN} / \mathrm{m}$ ), suggesting its preference for the polyunsaturated DDPE and DDPS rather than the saturated DSPC.

Influence of the acyl chains. The same method of analysis was then conducted for the comparison between saturated and unsaturated acyl chains. With the saturated phospholipids having the same type of acyl chain, the synergy values were higher for the phospholipids with PE 
or PC polar head group than with PS polar head group. Their MIP values followed the same trend, except for the shorter saturated chains for which DPPE, DPPS and DPPC all have similar MIP values. These binding parameters indicated that the saturated acyl chains promote the interaction between S100A10 and the phospholipids with PE and PC polar head group rather than with PS polar head group. In the presence of the unsaturated phospholipids, the synergy and MIP values were all higher for the phospholipids with PE or PS polar head group than with PC polar head group for each type of acyl chains (DO and DD), suggesting S100A10 prefers to interact with the unsaturated phospholipids with PE or PS polar head group than with the PC polar head group.

Discussion of the binding parameters. These observations on synergy and MIP values could be explained by the combination of hydrophobic, hydrophilic and electrostatic interactions between S100A10 and the phospholipids, as well as by the influence of the physical state of phospholipid monolayers and the steric hindrance effect of the different phospholipid polar head groups.

The S100A10 sequence is G P L G S M P Q M E H A M E T M M F T F H K F A G D K G Y L T K E D L R V L M E K E F G F L E N K D P L A V D I M K D L D Q C R D G K V G F Q S F F S L A G L T I A C N D Y F V V H M K Q K G K K, with hydrophobic amino acids highlighted in orange (according to Eisenberg hydrophobicity scale ${ }^{71}$ ). S100A10 thus 
contains $45 \%$ hydrophilic amino acids and 55\% hydrophobic amino acids. At $20^{\circ} \mathrm{C}$ (experimental temperature), the saturated phospholipids used in our study were all in a physical state of liquidcondensed phase. ${ }^{72}$ In this physical state, the protein insertion into phospholipid monolayers could be disadvantaged and the main interactions would thus be the hydrophilic ones between S100A10 and the polar head groups of phospholipids. Using an online protein tool (https://www.protpi.ch/Calculator/ProteinTool), it has been calculated that S100A10 has a pI of 6.99. S100A10 shows a slight negative charge (-0.43) at $\mathrm{pH} 7.30$, which could disrupt the interaction between S100A10 and phospholipids with a PS polar head group. This charge was calculated taking into account the five additional residues present at the $\mathrm{N}$-terminal of the protein (GPLGS) which were needed for the cleavage of the GST tag. Without this addition, the charge would be -0.86 at $\mathrm{pH} 7.30$, suggesting that this difference has little influence on the overall characteristics driving the interaction between S100A10 and phospholipids. The distribution of the negative charges mainly locates on the outside surface of the S100A10 homodimer, therefore leading to possible repulsive interactions with phospholipids with a PS polar head group (Figure S5). This property could explain why the saturated phospholipids with PS polar head group had lower synergy values than the saturated phospholipids with PE and PC polar head groups. However, 
several positive charges are also found on the outside surface, eventually counterbalancing this repulsive effect. At the same temperature $\left(20^{\circ} \mathrm{C}\right)$, the unsaturated phospholipids were all in a physical state of fluid phase. ${ }^{72}$ This physical state could advantage the S100A10 insertion into the phospholipid monolayers and there could be two main types of interactions: (1) hydrophilic interactions between S100A10 and polar head group of phospholipids and (2) hydrophobic interactions between S100A10 and acyl chains of phospholipids. Despite the fact that several hydrophobic residues are engaged into the inner core of the S100A10 homodimer, it still has several hydrophobic residues at the periphery (see Figure S6 where the hydrophobic residues are colored in orange) which could interact with the acyl chains according to the protein orientation. The interaction between S100A10 and unsaturated phospholipids with PS polar head group could thus be influenced by hydrophilic, hydrophobic and electrostatic interactions, and thus be promoted. This phenomenon could explain why the binding parameters values of unsaturated phospholipids with PS polar head group were higher than those of saturated phospholipids, especially for polyunsaturated phospholipids. For the same reasons, hydrophilic and hydrophobic interactions could advantage the interaction between S100A10 and unsaturated phospholipids with PE polar head group, where no electrostatic interaction can occur because of the zwitterionic polar 
head group, explaining the higher values of the binding parameters in the presence of unsaturated phospholipids.

Steric hindrance also appears to influence the S100A10 binding with unsaturated phospholipids.

Indeed, although DOPE, DOPC and DOPS have the same type of acyl chains, these three polar head groups nonetheless have different molecular areas. For comparison, at a surface pressure of $5 \mathrm{mN} / \mathrm{m}$, the areas per lipid are 85, 94 and $97 \AA^{2}$ for DOPE, DOPC and DOPS, respectively. ${ }^{73-74}$ Because DOPS has the highest value among these three monounsaturated phospholipids, it occupies a large space which advantages the interaction of S100A10 and leads to the highest MIP value among them. However, in the presence of polyunsaturated phospholipids (DD), the highest value is observed in the presence of PE polar head group, likely due to the contribution of charge repulsion between DOPS and S100A10.

According to our recent study, pAHNAK preferentially interacts with monounsaturated phospholipids and the highest MIP value was observed with DOPS $(58 \pm 5.6 \mathrm{mN} / \mathrm{m})$. The binding parameters analysis also showed a preferential interaction order for pAHNAK of DOPS $>$ DOPE $>$ DOPC. ${ }^{37}$ This order is the same for S100A10 for the MIP values, while the order seems to be DOPE > DOPS > DOPC for the synergy values. In order to better understand the interactions 
between the phospholipids and S100A10 and to compare its membrane binding to the one of pAHNAK, complementary studies were conducted with ellipsometry measurements to characterize the eventual insertion of the protein into the lipid monolayer.

Membrane behavior of S100A10 into the Phospholipid Monolayers. As the highest values of binding parameters were mainly observed in the presence of unsaturated phospholipids and for sake of comparison with pAHNAK, whose ellipsometry measurements were conducted with the monounsaturated lipids, the three phospholipids DOPC, DOPC and DOPE were used for the insertion study. These lipids are also more physiologically relevant, as most cellular lipids are at least partly unsaturated.

For S100A10 alone, the experimental ellipsometric angle $\Delta$ was $5.48^{\circ} \pm 0.26^{\circ}$, noted as $\Delta_{\mathrm{S} 100 \mathrm{~A} 10}$, which reflects the strong adsorption of S100A10 to the air-water interface (with the saturating concentration of S100A10 at $34.8 \mu \mathrm{g} / \mathrm{mL}$ ) and the large size of the protein (relative to the lipid monolayer thickness). Setting the initial surface pressure at $10 \mathrm{mN} / \mathrm{m}$, the ellipsometric angles for the monolayers of DOPS $\left(\Delta_{\mathrm{DOPS}}\right)$, DOPE $\left(\Delta_{\mathrm{DOPE}}\right)$ and DOPC $\left(\Delta_{\mathrm{DOPC}}\right)$ were found to be $1.52^{\circ} \pm$ $0.03^{\circ}, 1.27^{\circ} \pm 0.23^{\circ}$, and $0.87^{\circ} \pm 0.23^{\circ}$, respectively. These $\Delta$ values are significantly lower than those obtained for S100A10 alone due to the significant thickness difference between the initial 
low surface pressure lipid monolayer and the protein dimensions. The variation in $\Delta$ and hence films thickness, for these lipids, despite the same chain lengths, reflect differences due to multiple interrelated contributions including molecular areas, headgroup size and conformation and charge repulsion, which in turn affect the hydrophobic thickness of the acyl chains. In order to monitor the interaction between S100A10 and the phospholipids, $\Delta$ was measured as a function of time after the protein injection underneath the film until the surface pressure stabilized at $\Pi_{e}$ (Figure S7) $\Delta_{\mathrm{S} 100 \mathrm{~A} 10-\mathrm{DOPS}}, \Delta_{\mathrm{S} 100 \mathrm{~A} 10-\mathrm{DOPE}}$, and $\Delta_{\mathrm{S} 100 \mathrm{~A} 10-\mathrm{DOPC}}$ showed the values of $8.09^{\circ} \pm 0.37^{\circ}, 5.43^{\circ} \pm$ $0.06^{\circ}$, and $3.41^{\circ} \pm 0.50^{\circ}$, respectively (Figure 2 and Table S2), when the surface pressure reached equilibrium. For the interaction between S100A10 and a phospholipid monolayer of DOPS for example, the calculation for the expected $\Delta$ value was described in the Experimental Section, shown as the sum of $\Delta_{\mathrm{S} 100 \mathrm{~A} 10}$ and $\Delta_{\mathrm{DOPS}}$ which for DOPS, DOPE and DOPC, the expected values were calculated to be $6.99^{\circ} \pm 0.28^{\circ}, 6.75^{\circ} \pm 0.48^{\circ}$, and $6.35^{\circ} \pm 0.49^{\circ}$, respectively.

At the air-water interface, within the detection limit of the method, the ellipsometric angle $\psi$ value remains constant, additionally the differences in the refractive indices for the films are not considered (the relatively small variations in refractive indices, due to lipid or protein conformational changes, have limited impact on the optical thickness and hence the measured 
value of $\Delta) .{ }^{61,75-76}$ Thus, the ellipsometric angle $\Delta$ can be considered to be proportional to the total film thickness, as previously reported. ${ }^{53}$ The increases in surface pressure $(\Delta \Pi=10.3,4.2$ and $7.5 \mathrm{mN} / \mathrm{m}$ for DOPS, DOPE and DOPC, respectively) would in themselves yield only small to moderate increases in the lipid monolayer thickness. For the interaction between S100A10 and the DOPS monolayer, the experimental value $\left(8.09^{\circ} \pm 0.37^{\circ}\right)$ was higher than the expected value $\left(6.99^{\circ}\right.$ $\pm 0.28^{\circ}$ ). The high MIP value (discussed above) indicating strong interaction of the S100A10 with the DOPS monolayer, precludes that the S100A10 does not interact effectively with a DOPS monolayer yielding a higher than expected thickness due to the protein layer not being in close contact with the lipid headgroups, possibly separated by a layer of counterions. Rather, the experimental $\Delta$ suggests the orientation of S100A10 homodimer and/or the compactness of the folded state may have changed during the membrane binding, leading to an increase of the film thickness (as depicted in Figure 2) and commensurate increase in $\Delta$. Additionally, the moderate $\Delta \Pi$ (compared to that with DOPE and DOPC) may also implicate changes in the lipid film thickness, either from headgroup reorientations or chain extensions. The latter seems to be in more reasonable agreement with the high membrane binding parameters obtained for this system. For DOPE, the experimental value $\left(5.43^{\circ} \pm 0.06^{\circ}\right)$ was slightly lower than the expected value $(6.75 \pm$ 
0.48 ) and correlates well with the value measured for the protein alone. The ellipsometric value of delta represents an average over the entire region of interest selected thus if full penetration of the protein into the film occurred, the delta value should be lower than that of the protein alone (weighted average of area of protein and lipid coverages, respectively). Thus, it suggests a partial penetration of S100A10 homodimer into the DOPE monolayer and/or a conformational change of the protein (as illustrated in Figure 2). For DOPC, the experimental value was $3.41^{\circ} \pm 0.50^{\circ}$, which was significantly lower than the expected value $\left(6.35^{\circ} \pm 0.49^{\circ}\right)$. Furthermore, this experimental value was much lower than the ellipsometric angle $\Delta$ for the S100A10 homodimer alone $\left(5.48^{\circ} \pm\right.$ $0.26^{\circ}$ ), suggesting that in addition to penetration of the protein into the lipid film, a more significant reorganization has occurred within the S100A10 homodimer.

The ellipsometry measurements highlight a more complex behavior for the interaction between S100A10 and lipid monolayers of the three different monounsaturated phospholipids than was observed for pAHNAK. Indeed, the insertion of pAHNAK was deeper for DOPS and DOPC seemed to lead to a repulsion. The opposite trend is observed here with S100A10. Yet, it is not surprising because pAHNAK is a small peptide of 20 amino acids and it has a random structure while S100A10 has 102 amino acids per monomer and its homodimer has a more compact 3- 
dimensional structure. These two entities should have different roles in the membrane repair complex and thus different membrane behaviors. With the larger S100A10 protein, the possibility of different orientations and internal structural re-organizations plays a role.

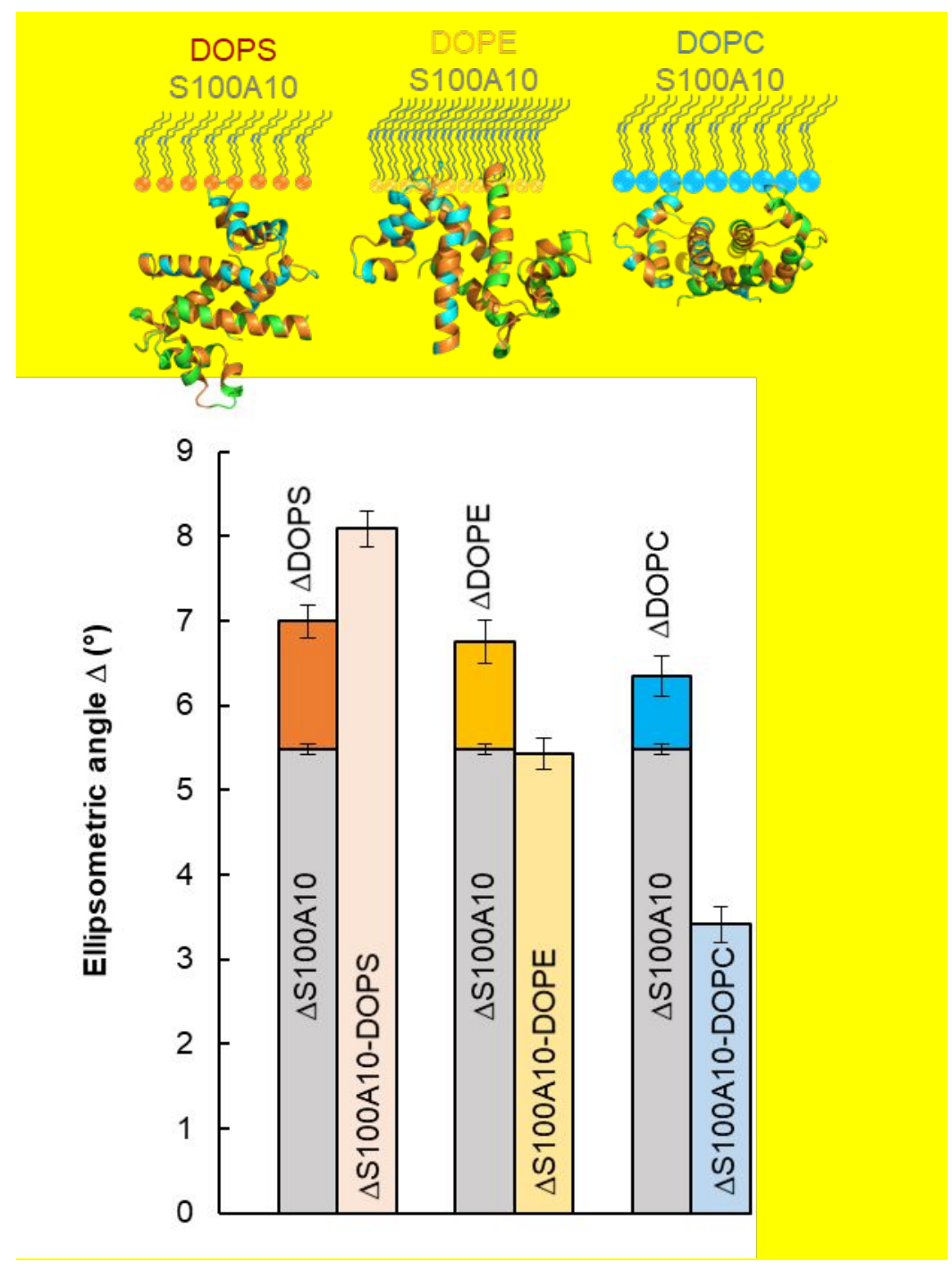

Figure 2. Expected and experimental values of the ellipsometric angles observed for the interaction between S100A10 and monounsaturated phospholipids (DOPS, DOPE, and DOPC) 
monolayers at $20^{\circ} \mathrm{C}$. A schematic representation of proposed interactions between S100A10 and each phospholipid monolayer is illustrated above the respective bar plot (Note that S100A10 comprises 2 monomers of one homodimer, denoted in green and blue, and the hydrophobic residues are colored in orange. [1BT6] created with PyMol, adapted Rety, S. et al. ${ }^{13}$ )

Interaction Between S100A10 and the Lipid Bilayers. To better assess the influence of the polar head group on its membrane binding with a complementary membrane model and to compare with the study of pAHNAK, solid-state NMR was performed with mixed lipid vesicles which is a bilayer model. In each phospholipid, the phosphorus atom possesses a chemical-shift anisotropy (CSA) as an NMR parameter related to the inclination of the phospholipid's polar head group, and its order parameter, which is due to its embedding lipid phase. When the CSA value decreases, this suggests either a moving of the phospholipid polar head toward the membrane plane or an increase of the membrane fluidity around the phospholipid. At a given ionic strength, the CSA increase, for example upon reducing the temperature, is usually interpreted as an increase of lipid rigidity. One-dimensional static NMR is often used for determining the CSA for phosphorus and globalmembrane rigidity, since overlapping spectra of lipid mixtures prevent to measure the CSA 
of individual lipids in the mixture at the same time. In order to separate those individual CSA values and obtain information on individual lipid mobility, it is necessary to use two-dimensional NMR and magic-angle spinning within the PROCSA pulse sequence (Figures S8 to S11). ${ }^{77}$ More than the actual value of the CSA, its variation upon changing the membrane environment is most interesting. For example, we have already shown that upon interaction with lipid membranes, pAHNAK specifically affected the CSA of PS, compared to those of PC and PE. ${ }^{37}$ In this study, 0 ppm was set for the isotropic chemical shift of DOPE, and the resonances of DOPS and DOPC were found at -0.10 and $-0.60 \mathrm{ppm}$ respectively, with a precision of $\pm 0.05 \mathrm{ppm}$.

From the application of PROCSA sequences on lipid bilayers alone and in the presence of S100A10, the CSA values of each phospholipid obtained are indicated in Figure 3 and Table S3.

Figure $3 \mathrm{a}$ and $3 \mathrm{~b}$ show the $\mathrm{CSA}$ results at $20^{\circ} \mathrm{C}$ and $37^{\circ} \mathrm{C}$ in bar plots, respectively. Without S100A10, all the CSA values decreased between $20^{\circ} \mathrm{C}$ and $37{ }^{\circ} \mathrm{C}$ showing, as expected, that the mobility of these phospholipids increased with temperature ${ }^{78-79}$. At $20^{\circ} \mathrm{C}$, the addition of S100A10 resulted in an increase of the CSA value for DOPS from $34.0 \pm 0.0$ to $36.5 \pm 0.7 \mathrm{ppm}$, suggesting the DOPS polar head group became more rigid. The CSA values for DOPE and DOPC almost did not change with the addition of S100A10. At $37^{\circ} \mathrm{C}$, a similar trend was observed. The CSA value 
for DOPS increased significantly with the addition of S100A10, from $27.0 \pm 0.0$ to $31.0 \pm 2.8$,

whereas that of DOPE and DOPC was not affected by the presence of S100A10.

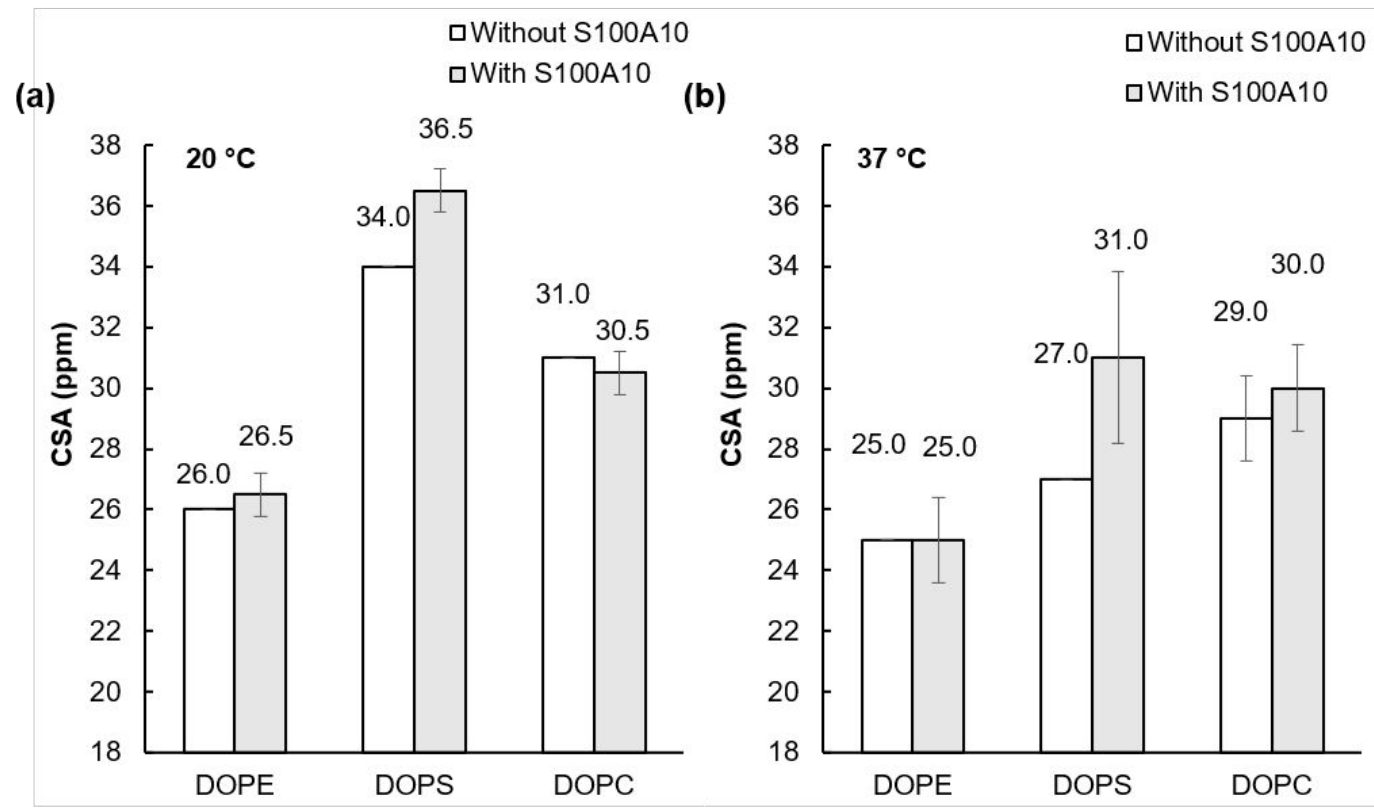

Figure 3. DOPE, DOPS and DOPC chemical-shift anisotropy (CSA) values obtained at $20^{\circ} \mathrm{C}$ (a)

and at $37^{\circ} \mathrm{C}$ (b), without (white) and with (gray) S100A10. When no error bar is shown, both

measurements gave the same value.

These findings suggest that at $20{ }^{\circ} \mathrm{C}$ and $37{ }^{\circ} \mathrm{C}$, S100A10 could interact with the polar head groups of DOPS and result in an increases rigidity of the PS polar head groups. At $37{ }^{\circ} \mathrm{C}$, this increasing of rigidity is more significant than that at $20{ }^{\circ} \mathrm{C}$, maybe because of an increase in the membrane fluidity, ${ }^{78-79}$ facilitating the insertion of S100A10 and the reduction of the PS polar head group mobility. With S100A10, as with pAHNAK, we observe a specific interaction with serine 
headgroups, affecting its CSA while leaving that of PC and PE almost unchanged. Nevertheless, both CSA changes are in opposite directions, indicating an increased lipid headgroup rigidity with S100A10, compared to an increased lipid headgroup flexibility with pAHNAK. S100A10 monomer has a molecular weight $(11.203 \mathrm{kDa})$ about 5 times larger than pAHNAK (2.310 kDa), is organized in homodimer, and has a much more compact 3-dimentional structure with $66 \%$ helix and 9.3\% $\beta$-strand (UniProt Knowledge Base, P60903) compared to the random structure of pAHNAK. ${ }^{37}$ Therefore, unlike pAHNAK which inserts into the acyl chains of DOPS and increases the mobility of PS polar head group region, ${ }^{37}$ it would probably be difficult for S100A10 to have the same behavior. A possible explanation is that S100A10 may partially insert into DOPS membrane and rigidify the PS polar head groups without any interaction with the acyl chains, as suggested by the ellipsometry measurements. However, S100A10 could neither influence the polar head group of DOPE, nor that of DOPC membrane at $20{ }^{\circ} \mathrm{C}$ and $37{ }^{\circ} \mathrm{C}$. Thus, the ${ }^{31} \mathrm{P}$ solid-state NMR measurements agree with the surface pressure measurements, suggesting that S100A10 prefers to interact with DOPS more than DOPE and DOPC, despite the potential for charge repulsion. These results, combined with those obtained by surface pressure and ellipsometry 
measurements, suggest S100A10 could change its orientation to interact more with the negatively

charged polar head groups than the zwitterionic ones.

\section{CONCLUSION}

The Langmuir monolayer experiments overall showed that S100A10 preferentially interacts

with unsaturated phospholipids. The ellipsometry measurements, combined with those performed

in surface tensiometry, suggested that S100A10 modifies the thickness of the interface and

orientation changes occur during its interactions with the lipid monolayers. Two-dimensional ${ }^{31} \mathrm{P}$

solid-state NMR studies of multilamellar vesicles revealed that S100A10 could interact more with

the negatively charged polar head groups than the zwitterionic ones. These observations lead to a

comprehensive model where, at $37^{\circ} \mathrm{C}$ in a physiological environment, S100A10 probably prefers

to interact with unsaturated phospholipids with negatively charged polar head groups. Our data

demonstrates potential interaction between S100A10 and phospholipids and, while no strong

membrane-binding assays such as co-sedimentation have been performed, these weak secondary

interactions of S100A10 could have a significant impact on the protein and/or membrane structure

and organization. Moreover, this finding matches with the conclusion of our recently study on 
pAHNAK, except that pAHNAK had an insertion into the acyl chains of DOPS, while S100A10 remains near the surface. Thus, both proteins, S100A10 and AHNAK, can probably interact with unsaturated phospholipids with negatively charged polar head groups. This new information improves our understanding of S100A10 membrane behavior and the cooperation between S100A10 and AHNAK. Even though the direct interaction between S100A10 and cell membrane lipids has never been reported before, our study shows the possible interactions between S100A10 and phospholipids, suggesting a role at the membrane during the cell membrane repair process. Many parameters can affect the membrane repair, including the recruitment of proteins and vesicles involved in the process, membrane composition, or ionic concentration. ${ }^{80-81}$ Once the integrity of the membrane is broken, the nearby phospholipids are among the first parameters that come into play. As a consequence, they will play a significant role in the membrane repair mechanism. Interestingly, it has been reported that their lipid composition in the membrane domains may be modified in some pathologies ${ }^{82-85}$ Lipids containing a PS head group are very important for membrane repair because of the particular affinity for this group of different main proteins involved in this process. For example, annexin A2 and S100A10-annexin A2 heterotetramer bind to vesicles containing anionic groups such as PS,, $35-36$ and Mitsugumin-53 
interacts with PS in order to facilitate the trafficking of vesicles containing PS to sites of membrane

lesions. ${ }^{86-87}$ Furthermore, the exposure of PS, usually observed during apoptosis, could also be a signal for the recruitment of proteins for efficient membrane repair and domains rich in lipids with PS could improve this process. The membrane interactions of other proteins in the dysferlin membrane repair complex need to be studied in the future, which will lead to a better understanding on the parameters which influence these membrane bindings and even impair the protein function.

\section{ASSOCIATED CONTENT}

\section{Supporting Information}

The Supporting Information is available free of charge at

Table of synergy and MIP values for S100A10 with the phospholipids tested. Table of experimental and expected values for the ellipsometric angles between S100A10 and monounsaturated phospholipids (DOPS, DOPE, and DOPC) monolayers at $20^{\circ} \mathrm{C}$. Table of DOPE, DOPS and DOPC chemical-shift anisotropy (CSA) values, without and with S100A10, at $20^{\circ} \mathrm{C}$ and $37^{\circ} \mathrm{C}$. Determination of S100A10 saturating concentration. Typical example of the determination of the binding parameters of S100A10 to a DPPC monolayer. Coomassie stained 
gel of purified S100A10. Circular dichroism spectra of S100A10 stored at different temperatures for 60 days compared with the spectrum obtained on day 0. S100A10 3D structure in homodimer with the positively charged residues colored in red and negatively charged residues colored in blue. S100A10 3D structure in homodimer with the hydrophobic residues colored in orange. Representation of ellipsometric angle $\Delta$ over time during the interaction between S100A10 and a DOPS monolayer. 2D-PROCSA ${ }^{31} \mathrm{P}$ solid-state NMR spectra at $20^{\circ} \mathrm{C}$ (before and after adding S100A10). Extracted 1D slices for DOPE, DOPS, and DOPC.

\section{AUTHOR INFORMATION}

\section{Corresponding Author}

Email: Elodie.boisselier@fmed.ulaval.ca

\section{Author Contributions}

EB, XY and DEW designed the study. DEW and IM, and CED contributed to NMR and ellipsometry setup, respectively. XY performed and analyzed the binding parameters study of S100A10. RML and HY performed the ellipsometric study of S100A10 and XY analyzed the data. 
KK performed the ${ }^{31} \mathrm{P}$ solid-state NMR study and DEW analyzed the data. XY and EB prepared the manuscript. DEW and CED reviewed and edited the manuscript. All the authors read and approved the final version of the manuscript.

\section{Notes}

The authors declare no competing financial interest.

\section{ACKNOWLEDGMENTS}

The authors are indebted to the Natural Sciences and Engineering Research Council of Canada (NSERC, \#RGPIN-2015-04815 to EB, \#RGPIN-2018-06200 to IM and \# RGPIN-2019-07043 to CED), the Quebec Network for Research on Protein Function, Engineering, and Applications (PROTEO), the Eye Disease Foundation, the CHU de Québec Foundation and the Centre National de la Recherche Scientifique (UMR 7203 to DEW) for their financial support. EB is a research scholar from the Fonds de Recherche du Québec - Santé (FRQS, \#282713). XY is a PhD student and received a scholarship from PROTEO. KK is a $\mathrm{PhD}$ student supported by a scholarship from UQAM. The authors are very grateful for the prolific environment provided by their research centers, e.g. the Quebec Network for Research on Protein Function, Engineering, and Applications 
- PROTEO (IM and EB), the Research Center Dedicated to the Development, Study and Use of

New Materials - CERMA (EB), the Quebec Center for Advanced Materials - QCAM (CED and EB) and the Vision Health Research Network (VHRN).

\section{REFERENCES}

1. Moore, B. W., A soluble protein characteristic of the nervous system. Biochem Biophys Res Commun 1965, 19(6), 739-44.

2. Gonzalez, L. L.; Garrie, K.; Turner, M. D., Role of S100 proteins in health and disease. Biochim Biophys Acta Mol Cell Res 2020, 1867 (6), 118677.

3. Sedaghat, F.; Notopoulos, A., S100 protein family and its application in clinical practice. Hippokratia 2008, 12(4), 198-204.

4. $\quad$ Contzler, R.; Favre, B.; Huber, M.; Hohl, D., Cornulin, a new member of the "fused gene" family, is expressed during epidermal differentiation. J Invest Dermatol 2005, 124 (5), 990-7.

5. Fleming, J. M.; Ginsburg, E.; Oliver, S. D.; Goldsmith, P.; Vonderhaar, B. K., Hornerin, an S100 family protein, is functional in breast cells and aberrantly expressed in breast cancer. BMC Cancer 2012, 12, 266.

6. Garreis, F.; Jahn, J.; Wild, K.; Abrar, D.; Schicht, M.; Schröder, J.; Paulsen, F., Expression and Regulation of S100 Fused-Type Protein Hornerin at the Ocular Surface and Lacrimal Apparatus. Invest Ophthalmol Vis Sci 2017, 58 (13), 5968-5977.

7. Wu, Z.; Hansmann, B.; Meyer-Hoffert, U.; Glaser, R.; Schroder, J. M., Molecular identification and expression analysis of filaggrin-2, a member of the S100 fused-type protein family. PLoS One 2009, 4(4), e5227.

8. $\quad$ Krieg, P.; Schuppler, M.; Koesters, R.; Mincheva, A.; Lichter, P.; Marks, F., Repetin (Rptn), a new member of the "fused gene" subgroup within the S100 gene family encoding a murine epidermal differentiation protein. Genomics 1997, 43(3), 339-48. 
9. Donato, R., S100: a multigenic family of calcium-modulated proteins of the EF-hand type with intracellular and extracellular functional roles. Int J Biochem Cell Biol 2001, 33 (7), 637-68.

10. Santamaria-Kisiel, L.; Rintala-Dempsey, A. C.; Shaw, G. S., Calcium-dependent and independent interactions of the S100 protein family. Biochem J2006, 396 (2), 201-14.

11. Weinman, S., Calcium-binding proteins: an overview. J Biol Buccale 1991, 19(1), 90-8. 12. Kretsinger, R. H.; Nockolds, C. E., Carp Muscle Calcium-binding Protein. Journal of Biological Chemistry 1973, 248 (9), 3313-3326.

13. Réty, S.; Sopkova, J.; Renouard, M.; Osterloh, D.; Gerke, V.; Tabaries, S.; Russo-Marie, F.; Lewit-Bentley, A., The crystal structure of a complex of p11 with the annexin II N-terminal peptide. Nat Struct Biol 1999, 6(1), 89-95.

14. Santamaria-Kisiel, L.; Shaw, G. S., Identification of regions responsible for the open conformation of S100A10 using chimaeric S100A11-S100A10 proteins. Biochem J2011, 434 (1), 37-48.

15. Bertini, I.; Borsi, V.; Cerofolini, L.; Das, G., S. ; Fragai, M.; Luchinat, C., Solution structure and dynamics of human S100A14. J Biol Inorg Chem 2013, 18 (2), 183-194.

16. Zhu, M.; Wang, H.; Cui, J.; Li, W.; An, G.; Pan, Y.; Zhang, Q.; Xing, R.; Lu, Y., Calcium-binding protein S100A14 induces differentiation and suppresses metastasis in gastric cancer. Cell Death Dis 2017, 8 (7), e2938.

17. Gerke V, W. K., Calcium-dependent conformational changes in the 36-kDa subunit of intestinal protein I related to the cellular $36-\mathrm{kDa}$ target of Rous sarcoma virus tyrosine kinase. $J$ Biol Chem 1985, 260 (3), 1688-95.

18. Spratt, D. E.; Barber, K. R.; Marlatt, N. M.; Ngo, V.; Macklin, J. A.; Xiao, Y.; Konermann, L.; Duennwald, M. L.; Shaw, G. S., A subset of calcium-binding S100 proteins show preferential heterodimerization. FEBS J2019, 286 (10), 1859-1876.

19. Miwa, N.; Uebi, T.; Kawamura, S., S100-annexin complexes--biology of conditional association. FEBS J 2008, 275 (20), 4945-55.

20. Rintala-Dempsey, A. C.; Rezvanpour, A.; Shaw, G. S., S100-annexin complexes-structural insights. FEBS J2008, $275(20)$, 4956-66.

21. Donato, R., Intracellular and extracellular roles of S100 proteins. Microsc Res Tech 2003, $60(6), 540-51$. 
22. Madureira, P. A.; O'Connell, P. A.; Surette, A. P.; Miller, V. A.; Waisman, D. M., The biochemistry and regulation of S100A10: a multifunctional plasminogen receptor involved in oncogenesis. J Biomed Biotechnol 2012, 2012, 353687.

23. Donato, R.; Cannon, B. R.; Sorci, G.; Riuzzi, F.; Hsu, K.; Weber, D. J.; Geczy, C. L., Functions of S100 Proteins. Curr Mol Med2013, 13 (1), 24-57.

24. Chen, H.; Xu, C.; Jin, Q.; Liu, Z., S100 protein family in human cancer. Am J Cancer Res. 2014, 4 (2), 89-115.

25. Lauritzen, S. P.; Boye, T. L.; Nylandsted, J., Annexins are instrumental for efficient plasma membrane repair in cancer cells. Semin Cell Dev Biol 2015, 45, 32-8.

26. Nakata, T.; Sobue, K.; Hirokawa, N., Conformational change and localization of calpactin I complex involved in exocytosis as revealed by quick-freeze, deep-etch electron microscopy and immunocytochemistry. J Cell Biol. 1990, 110(1), 13-25.

27. Rezvanpour, A.; Santamaria-Kisiel, L.; Shaw, G. S., The S100A10-annexin A2 complex provides a novel asymmetric platform for membrane repair. J Biol Chem 2011, 286(46), 4017483.

28. Cacciottolo, M.; Belcastro, V.; Laval, S.; Bushby, K.; di Bernardo, D.; Nigro, V., Reverse engineering gene network identifies new dysferlin-interacting proteins. J Biol Chem 2011, 286 (7), 5404-13.

29. de Morree, A.; Hensbergen, P. J.; van Haagen, H. H.; Dragan, I.; Deelder, A. M.; t Hoen, P. A.; Frants, R. R.; van der Maarel, S. M., Proteomic analysis of the dysferlin protein complex unveils its importance for sarcolemmal maintenance and integrity. PLoS One 2010, 5(11), e13854.

30. Leung, C.; Utokaparch, S.; Sharma, A.; Yu, C.; Abraham, T.; Borchers, C.; Bernatchez, P., Proteomic identification of dysferlin-interacting protein complexes in human vascular endothelium. Biochem Biophys Res Commun 2011, 415(2), 263-9.

31. Draeger, A.; Monastyrskaya, K.; Babiychuk, E. B., Plasma membrane repair and cellular damage control: the annexin survival kit. Biochem Pharmacol 2011, 81 (6), 703-12.

32. Han, R.; Campbell, K., Dysferlin and muscle membrane repair. Curr Opin Cell Biol. 2007, $19(4), 409-16$.

33. Idone, V.; Tam, C.; Andrews, N. W., Two-way traffic on the road to plasma membrane repair. Trends Cell Biol 2008, $18(11), 552-9$. 
34. Dempsey, B. R.; Rezvanpour, A.; Lee, T. W.; Barber, K. R.; Junop, M. S.; Shaw, G. S., Structure of an asymmetric ternary protein complex provides insight for membrane interaction. Structure 2012, 20(10), 1737-45.

35. Waisman, D. M., Annexin II tetramer: structure and function. Mol Cell Biochem 1995, 149-150, 301-22.

36. Bharadwaj, A.; Bydoun, M.; Holloway, R.; Waisman, D., Annexin A2 heterotetramer: structure and function. Int J Mol Sci 2013, 14 (3), 6259-305.

37. Yan, X.; Noel, F.; Marcotte, I.; DeWolf, C. E.; Warschawski, D.; Boisselier, E., AHNAK C-terminal peptide membrane binding - Interactions between the residues 5654-5673 of AHNAK and phospholipid monolayers and bilayers. Langmuir 2019, 36(1), 362-369.

38. Benaud, C.; Gentil, B. J.; Assard, N.; Court, M.; Garin, J.; Delphin, C.; Baudier, J., AHNAK interaction with the annexin 2/S100A10 complex regulates cell membrane cytoarchitecture. J Cell Biol 2004, 164 (1), 133-44.

39. De Seranno, S.; Benaud, C.; Assard, N.; Khediri, S.; Gerke, V.; Baudier, J.; Delphin, C., Identification of an AHNAK binding motif specific for the Annexin2/S100A10 tetramer. J Biol Chem 2006, 281 (46), 35030-8.

40. Grill, D.; Matos, A. L. L.; de Vries, W. C.; Kudruk, S.; Heflik, M.; Dorner, W.; Mootz, H. D.; Jan Ravoo, B.; Galla, H. J.; Gerke, V., Bridging of membrane surfaces by annexin A2. Sci $\operatorname{Rep} 2018,8(1), 14662$.

41. Rescher, U.; Ruhe, D.; Ludwig, C.; Zobiack, N.; Gerke, V., Annexin 2 is a phosphatidylinositol (4,5)-bisphosphate binding protein recruited to actin assembly sites at cellular membranes. J Cell Sci 2004, 117(Pt 16), 3473-80.

42. Rescher, U.; Gerke, V., Annexins--unique membrane binding proteins with diverse functions. J Cell Sci 2004, 117 (Pt 13), 2631-9.

43. Hayes, M. J.; Shao, D.; Bailly, M.; Moss, S. E., Regulation of actin dynamics by annexin 2. EMBO J2006, 25(9), 1816-26.

44. Johnsson, N.; Marriott, G.; Weber, K., p36, the major cytoplasmic substrate of src tyrosine protein kinase, binds to its p11 regulatory subunit via a short amino-terminal amphiphatic helix. EMBO J1988, 7(8), 2435-42. 
45. Gokhale, N. A.; Abraham, A.; Digman, M. A.; Gratton, E.; Cho, W., Phosphoinositide specificity of and mechanism of lipid domain formation by annexin A2-p11 heterotetramer. $J$ Biol Chem 2005, 280 (52), 42831-40.

46. Stefaniu, C.; Brezesinski, G.; Mohwald, H., Langmuir monolayers as models to study processes at membrane surfaces. Adv Colloid Interface Sci 2014, 208, 197-213.

47. Boisselier, E.; Demers, E.; Cantin, L.; Salesse, C., How to gather useful and valuable information from protein binding measurements using Langmuir lipid monolayers. Adv Colloid Interface Sci 2017, 243, 60-76.

48. Page, R. C.; Li, C.; Hu, J.; Gao, F. P.; Cross, T. A., Lipid bilayers: an essential environment for the understanding of membrane proteins. Magn Reson Chem 2007, 45 Suppl 1, S2-11.

49. Boisselier, E.; Calvez, P.; Demers, E.; Cantin, L.; Salesse, C., Effect of oxidation of polyunsaturated phospholipids on the binding of proteins in monolayers. Colloids Surf B Biointerfaces 2013, 109, 109-14.

50. Yan, X.; Lebel-Beaucage, M.-F.; Tremblay, S.; Cantin, L.; Shaw, G. S.; Boisselier, E., Optimized transformation, overexpression and purification of S100A10. Biotechniques 2019, 67 (5), 246-248.

51. Wilhelmy, L., Ueber die Abhängigkeit der Capillaritäts-Constanten des Alkohols von Substanz und Gestalt des benetzten festen Körpers. 1863; Vol. 195, p 177-217.

52. Elderdfi, M.; Sikorski, A. F., Langmuir-monolayer methodologies for characterizing protein-lipid interactions. Chem Phys Lipids 2018, 212, 61-72.

53. Calvez, P.; Demers, E.; Boisselier, E.; Salesse, C., Analysis of the contribution of saturated and polyunsaturated phospholipid monolayers to the binding of proteins. Langmuir 2011, $27(4), 1373-9$.

54. Calvez, P.; Schmidt, T. F.; Cantin, L.; Klinker, K.; Salesse, C., Phosphatidylserine Allows Observation of the Calcium-Myristoyl Switch of Recoverin and Its Preferential Binding. J Am Chem Soc 2016, 138 (41), 13533-13540.

55. Calvez, P.; Bussieres, S.; Eric, D.; Salesse, C., Parameters modulating the maximum insertion pressure of proteins and peptides in lipid monolayers. Biochimie 2009, 91 (6), 718-33. 
56. Hoareau, E.; Belley, N.; Klinker, K.; Desbat, B.; Boisselier, E., Characterization of neurocalcin delta membrane binding by biophysical methods. Colloids Surf B Biointerfaces 2019, 174, 291-299.

57. Lemire, S.; Jeromin, A.; Boisselier, E., Membrane binding of Neuronal Calcium Sensor-1 (NCS1). Colloids Surf B Biointerfaces 2016, 139, 138-47.

58. Demers, É.; Boisselier, É.; Horchani, H.; Blaudez, D.; Calvez, P.; Cantin, L.; Belley, N.; Champagne, S.; Desbat, B.; Salesse, C., Lipid Selectivity, Orientation, and Extent of Membrane Binding of Nonacylated RP2. Biochemistry 2015, 54 (16), 2560-2570.

59. Boisselier, E.; Calvez, P.; Demers, E.; Cantin, L.; Salesse, C., Influence of the physical state of phospholipid monolayers on protein binding. Langmuir 2012, 28(25), 9680-8.

60. Mansuri, E.; Zepeda-Velazquez, L.; Schmidt, R.; Brook, M. A.; DeWolf, C. E., Surface Behavior of Boronic Acid-Terminated Silicones. Langmuir 2015, 31 (34), 9331-9.

61. Finot, E.; Markey, L.; Hane, F.; Amrein, M.; Leonenko, Z., Combined atomic force microscopy and spectroscopic ellipsometry applied to the analysis of lipid-protein thin films. Colloids Surf B Biointerfaces 2013, 104, 289-93.

62. Rezvanpour, A.; Phillips, J. M.; Shaw, G. S., Design of high-affinity S100-target hybrid proteins. Protein Sci 2009, 18 (12), 2528-36.

63. Maggio, B.; Cumar, F.; Caputto, R., Interactions of gangliosides with phospholipids and glycosphingolipids in mixed monolayers. Biochem J. 1978, $175(3), 1113-8$.

64. Lee, A. G., How lipids affect the activities of integral membrane proteins. Biochim Biophys Acta 2004, 1666 (1-2), 62-87.

65. Demel, R. A.; Geurts van Kessel, W. S.; Zwaal, R. F.; Roelofsen, B.; van Deenen, L. L., Relation between various phospholipase actions on human red cell membranes and the interfacial phospholipid pressure in monolayers. Biochim Biophys Acta 1975, 406(1), 97-107.

66. Eibl, H.; Blume, A., The influence of charge on phosphatidic acid bilayer membranes. Biochim Biophys Acta. 1979, 553 (3), 476-88.

67. Moreau, H.; Pieroni, G.; Jolivet-Reynaud, C.; Alouf, J. E.; Verger, R., A new kinetic approach for studying phospholipase $\mathrm{C}$ (Clostridium perfringens alpha toxin) activity on phospholipid monolayers. Biochemistry 1988, 27(7), 2319-23. 
68. LaRocca, T. J.; Pathak, P.; Chiantia, S.; Toledo, A.; Silvius, J. R.; Benach, J. L.; London, E., Proving lipid rafts exist: membrane domains in the prokaryote Borrelia burgdorferi have the same properties as eukaryotic lipid rafts. PLoS Pathog 2013, 9(5), e1003353.

69. Marsh, D., Lateral pressure in membranes. Biochim Biophys Acta. 1996, $1286(3), 183-$ 223.

70. Boguslavsky, V.; Rebecchi, M.; Morris, A. J.; Jhon, D. Y.; Rhee, S. G.; McLaughlin, S., Effect of monolayer surface pressure on the activities of phosphoinositide-specific phospholipase C-beta 1, -gamma 1, and -delta 1. Biochemistry 1994, 33 (10), 3032-7.

71. Eisenberg, D.; Schwarz, E.; Komaromy, M.; Wall, R., Analysis of membrane and surface protein sequences with the hydrophobic moment plot. J Mol Biol 1984, $179(1), 125-42$.

72. Luckey, M., Membrane Structural Biology Cambridge University Press: 2014; p 19.

73. Moghaddam, B.; McNeil, S. E.; Zheng, Q.; Mohammed, A. R.; Perrie, Y., Exploring the correlation between lipid packaging in lipoplexes and their transfection efficacy. Pharmaceutics 2011, $3(4), 848-64$.

74. Mingotaud, A. F.; Mingotaud, É.; Patterson, L. K., Handbook of Monolayers. Academic Press: London, 1993; Vol. 1, p 863-944.

75. Lopez-Montero, I.; Lopez-Navajas, P.; Mingorance, J.; Rivas, G.; Velez, M.; Vicente, M.; Monroy, F., Intrinsic disorder of the bacterial cell division protein ZipA: coil-to-brush conformational transition. FASEB J2013, 27 (8), 3363-75.

76. Pfrang, C.; Sebastiani, F.; Lucas, C. O.; King, M. D.; Hoare, I. D.; Chang, D.; Campbell, R. A., Ozonolysis of methyl oleate monolayers at the air-water interface: oxidation kinetics, reaction products and atmospheric implications. Phys Chem Chem Phys 2014, 16 (26), 13220-8. 77. Warschawski, D. E.; Arnold, A. A.; Marcotte, I., A New Method of Assessing Lipid Mixtures by (31)P Magic-Angle Spinning NMR. Biophys J 2018, 114 (6), 1368-1376.

78. Papahadjopoulos, D.; Jacobson, K.; Nir, S.; Isac, T., Phase transitions in phospholipid vesicles. Fluorescence polarization and permeability measurements concerning the effect of temperature and cholesterol. Biochim Biophys Acta. 1973, 311 (3), 330-48.

79. Al-Ahmady, Z.; Kostarelos, K., Chemical Components for the Design of TemperatureResponsive Vesicles as Cancer Therapeutics. Chem Rev 2016, 116 (6), 3883-918.

80. $\quad$ Andrews, N. W.; Corrotte, M., Plasma membrane repair. Curr Biol 2018, 28 (8), R392R397. 
81. Jimenez, A. J.; Perez, F., Plasma membrane repair: the adaptable cell life-insurance. Curr Opin Cell Biol 2017, 47, 99-107.

82. Koehrer, P.; Saab, S.; Berdeaux, O.; Isaico, R.; Gregoire, S.; Cabaret, S.; Bron, A. M.; Creuzot-Garcher, C. P.; Bretillon, L.; Acar, N., Erythrocyte phospholipid and polyunsaturated fatty acid composition in diabetic retinopathy. PLoS One 2014, 9 (9), e106912.

83. Wojcik-Baszko, D.; Charkiewicz, K.; Laudanski, P., Role of dyslipidemia in preeclampsia-A review of lipidomic analysis of blood, placenta, syncytiotrophoblast microvesicles and umbilical cord artery from women with preeclampsia. Prostaglandins Other Lipid Mediat 2018, 139, 19-23.

84. Li, S.; Ganguli-Indra, G.; Indra, A. K., Lipidomic analysis of epidermal lipids: a tool to predict progression of inflammatory skin disease in humans. Expert Rev Proteomics 2016, 13 (5), 451-6.

85. Fonteh, A. N.; Harrington, R. J.; Huhmer, A. F.; Biringer, R. G.; Riggins, J. N.;

Harrington, M. G., Identification of disease markers in human cerebrospinal fluid using lipidomic and proteomic methods. Dis Markers 2006, 22 (1-2), 39-64.

86. Cai, C.; Masumiya, H.; Weisleder, N.; Matsuda, N.; Nishi, M.; Hwang, M.; Ko, J. K.; Lin, P.; Thornton, A.; Zhao, X.; Pan, Z.; Komazaki, S.; Brotto, M.; Takeshima, H.; Ma, J., MG53 nucleates assembly of cell membrane repair machinery. Nat Cell Biol 2009, 11 (1), 56-64. 87. McNeil, P., Membrane repair redux: redox of MG53. Nat Cell Biol 2009, 11 (1), 7-9. 
Table of Contents:

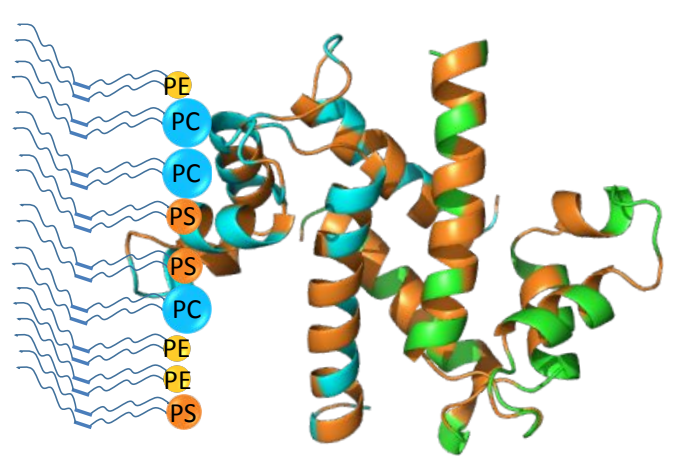

In a physiological environment at $37^{\circ} \mathrm{C}, \mathrm{S} 100 \mathrm{~A} 10$ probably prefers to interact with unsaturated phospholipids with negatively charged polar head groups, and partially inserts into the membrane to interact with the polar head groups. 